\title{
When does transapical aortic valve replacement become a futile procedure? An analysis from a national registry
}

\author{
Augusto D’Onofrio, MD, PhD, ${ }^{a}$ Stefano Salizzoni, $\mathrm{MD}, \mathrm{PhD},{ }^{\mathrm{b}}$ Marco Agrifoglio, $\mathrm{MD}, \mathrm{PhD},{ }^{\mathrm{c}}$ \\ Vincenzo Lucchetti, MD, ${ }^{\mathrm{d}}$ Francesco Musumeci, MD, ${ }^{\mathrm{e}}$ Giampiero Esposito, MD, ${ }^{\mathrm{f}}$ Paolo Magagna, MD, ${ }^{\mathrm{g}}$ \\ Marco Aiello, MD, ${ }^{\mathrm{h}}$ Carlo Savini, MD, ${ }_{\mathrm{i}}^{\mathrm{i}}$ Mauro Cassese, MD,${ }_{\mathrm{j}}^{\mathrm{j}}$ Mattia Glauber, MD, ${ }_{\mathrm{k}}^{\mathrm{k}}$ Giuseppe Punta, MD, \\ Ottavio Alfieri, MD, ${ }^{\mathrm{m}}$ Davide Gabbieri, MD,${ }^{\mathrm{n}}$ Domenico Mangino, $\mathrm{MD},{ }^{\circ}$ Andrea Agostinelli, MD, PhD, ${ }^{\mathrm{p}}$ \\ Ugolino Livi, MD, ${ }^{\mathrm{q}}$ Omar Di Gregorio, MD,${ }^{\mathrm{r}}$ Alessandro Minati, MD, ${ }^{\mathrm{s}}$ Giuseppe Faggian, $\mathrm{MD},{ }^{\mathrm{t}}$ \\ Claudia Filippini, BSc, ${ }^{b}$ Mauro Rinaldi, MD, ${ }^{b}$ and Gino Gerosa, MD $^{\mathrm{a}}$
}

Objectives: Patient selection is crucial to achieve good outcomes and to avoid futile procedures in patients undergoing transcatheter aortic valve replacement. The aim of this multicenter retrospective study was to identify independent predictors of 1-year mortality in patients surviving after transapical transcatheter aortic valve replacement.

Methods: We analyzed data from the Italian registry of transapical transcatheter aortic valve replacement that includes patients undergoing operation in 21 centers from 2007 to 2012. Futility was defined as mortality within 1 year after transapical transcatheter aortic valve replacement in patients surviving at 30 days. Thirty-day survivors were divided in 2 groups: futility (group F) and nonfutility (group NF). Cox proportional hazard regression analysis was performed to identify independent predictors of futility.

Results: We analyzed data from 645 patients with survival of 30 days or more after transapical transcatheter aortic valve replacement. Groups $F$ and NF included 60 patients $(10.8 \%)$ and 585 patients $(89.2 \%)$, respectively. Patients in group $\mathrm{F}$ were more likely to have insulin-dependent diabetes $(15 \%$ vs $7.2 \%, P=.03)$, creatinine 2.0 $\mathrm{mg} / \mathrm{dL}$ or greater or dialysis $(18.3 \%$ vs $8.2 \%, P=.01)$, logistic European System for Cardiac Operative Risk Evaluation greater than $20 \%(66.7 \%$ vs $50.3 \%, P=.02)$, preoperative rhythm disorders $(40 \%$ vs $25.3 \%$, $P=.03)$, critical preoperative state $(8.3 \%$ vs $1.8 \%, P=.002)$, and left ventricular ejection fraction less than $30 \%(15 \%$ vs $2.9 \%, P<.001)$. The multivariate analysis identified the following as independent predictors of futility: insulin-dependent diabetes (odds ratio, $3.1 ; P=.003$ ), creatinine $2.0 \mathrm{mg} / \mathrm{dL}$ or greater or dialysis (odds ratio, 2.52; $P=.012$ ), preoperative rhythm disorders (odds ratio, 1.88; $P=.04$ ), and left ventricular ejection fraction less than $30 \%$ (odds ratio, $4.34 ; P=.001$ ).

Conclusions: According to our data, among patients undergoing transapical transcatheter aortic valve replacement, those with insulin-dependent diabetes, advanced chronic kidney disease, rhythm disorders, and low left ventricular ejection fraction have a higher risk to undergo futile procedures. (J Thorac Cardiovasc Surg 2014;148:973-80)

Transcatheter aortic valve replacement (TAVR) is a well-established technique for inoperable or high-risk patients with severe symptomatic aortic valve stenosis because it has shown good short- and midterm clinical

From the Division of Cardiac Surgery, ${ }^{\mathrm{a}}$ University of Padova, Padova, Italy; Division of Cardiac Surgery, ${ }^{\mathrm{b}}$ University of Torino, Torino, Italy; Division of Cardiac Surgery, ${ }^{\mathrm{c}}$ Monzino Hospital, Milano, Italy; Division of Cardiac Surgery, ${ }^{\mathrm{d}}$ Clinica Montevergine, Mercogliano, Italy; Department of Cardiac Surgery, ${ }^{e}$ San Camillo Hospital, Roma, Italy; Division of Cardiac Surgery, ${ }^{\mathrm{f}}$ Humanitas Gavazzeni Hospital, Bergamo and Rozzano, Italy; Division of Cardiac Surgery, ${ }^{\mathrm{g}}$ San Bortolo Hospital, Vicenza, Italy; Division of Cardiac Surgery, ${ }^{\text {h }}$ University of Pavia, Pavia, Italy; Division of Cardiac Surgery, ${ }^{\mathrm{i}}$ Policlinico S. Orsola Malpighi, Bologna, Italy; Division of Cardiac Surgery, ${ }^{j}$ Clinica S. Maria, Bari, Italy; Ospedale del Cuore, ${ }^{k}$ Fondazione Monastiero, Massa, Italy; Division of Cardiac Surgery, ${ }^{1}$ Ordine Mauriziano Hospital, Torino, Italy; San Raffaele University Hospital, ${ }^{\mathrm{m}}$ Milano, Italy; Cardiac Surgery, Hesperia Hospital, ${ }^{\mathrm{n}}$ Modena, Italy; Division of Cardiac Surgery, ${ }^{\circ}$ Ospedale dell'Angelo, Mestre, Italy; Division of Cardiac Surgery, ${ }^{\mathrm{p}}$ University of Parma, Parma, Italy; Division of Cardiac Surgery, ${ }^{\mathrm{q}}$ S. Maria della Misericordia Hospital, Udine, Italy; Division of Cardiac Surgery, ${ }^{r}$ S. Croce e Carle Hospital, Cuneo, Italy; Division of Cardiac Surgery, ${ }^{\mathrm{s}}$ Azienda Ospedaliera-Universitaria, Trieste, Italy; and Cardiovascular Surgery, ${ }^{\mathrm{t}}$ University of Verona, Verona, Italy. Disclosures: Drs D'Onofrio and Aiello report consulting fees from Edwards Lifesciences. Dr Cassese reports consulting fees from Edwards Lifesciences and and hemodynamic outcomes. ${ }^{1-5}$ Despite TAVR rapid diffusion during the last few years, concerns still exist about the appropriateness of use of such expensive technology in elderly patients with multiple

Medtronic, as well as lecture fees from Medtronic. Dr Glauber reports consulting fees from Sorin, and lecture fees from Sorin and Medtronic. Dr Rinaldi reports consulting fees from Edwards Lifesciences and lecture fees from Edwards Lifesciences, Medtronic, and Novartis. Dr Gerosa reports consulting fees from AstraZeneca, lecture fees from HeartWare and St. Jude Medical, and grant support from Edwards. All other authors have nothing to disclose with regard to commercial support.

Read at the 94th Annual Meeting of The American Association for Thoracic Surgery, Toronto, Ontario, Canada, April 26-30, 2014.

Drs D'Onofrio and Salizzoni contributed equally to this article, and both are considered first authors.

Received for publication April 10, 2014; revisions received May 28, 2014; accepted for publication June 5, 2014; available ahead of print July 10, 2014.

Address for reprints: Augusto D'Onofrio, MD, PhD, Division of Cardiac Surgery, University of Padova, Via Giustiniani 2, 35128 Padova, Italy (E-mail: adonofrio@hotmail.it).

0022-5223/\$36.00

Copyright (c) 2014 by The American Association for Thoracic Surgery

http://dx.doi.org/10.1016/j.jtcvs.2014.06.015 


$\begin{array}{ll}\text { Abbreviations and Acronyms } \\ \text { euroSCORE }= & \text { European System for Cardiac } \\ & \text { Operative Risk Evaluation } \\ = & \text { Italian Registry of Trans-Apical } \\ & \text { Aortic Valve Implantation } \\ \text { I-TA } & \text { left ventricular ejection fraction } \\ & =\text { odds ratio } \\ \text { LVEF } & \text { quality-adjusted life year } \\ \text { OR } & \text { transapical transcatheter aortic valve } \\ \text { QALY } & \text { replacement } \\ \text { TA-TAVR } & \text { transcatheter aortic valve } \\ & \text { replacement } \\ \text { TAVR } & \text { Valve Academic Research } \\ & \text { Consortium }\end{array}$

comorbidities. ${ }^{6}$ In fact, TAVR is expensive in terms of cost of devices and of human, structural, and logistic resources. It has been demonstrated that patient selection is crucial to achieve good postoperative outcomes after TAVR. ${ }^{7}$ Cost-effectiveness studies on TAVR focus their attention on the gain of quality-adjusted life years (QALYs); consequently poor postoperative survival, even if it occurs after an uneventful operation, will result in an ineffective procedure under both the clinical and the financial point of views. Therefore, the selection of very elderly patients or patients with extremely high preoperative risk profiles may lead to technically successful operations but also to short postoperative survival, thus making futile such an expensive and complex procedure. In particular, the cost-effectiveness of transapical TAVR (TA-TAVR) is less evident than transfemoral TAVR. ${ }^{8,9}$ Thus, particular attention should be given during the evaluation of patients for TA-TAVR. Several studies have reported on the predictors of 30-day and 1 -year mortality in patients undergoing $\mathrm{TAVR}^{1,10-14}$; however, there are a lack of data on the clinical features of patients who survive the procedure and are successfully discharged from the hospital but then die early during follow-up. The identification of predictors of early mortality in patients surviving TA-TAVR may help to better select TAVR candidates to optimize results and use of resources and may also help to identify the patients with a high risk of early death after a successful operation to improve preoperative counseling with patients and their families. For this reason, in the present retrospective multicenter study, we aimed at identifying the independent predictors of 1-year mortality in patients surviving after TA-TAVR.

\section{METHODS}

Patient-informed consent for treatment and data collection and analysis for scientific purposes was always collected; the ethics committees approved the data collection of patients undergoing TAVR. Indications for TA-TAVR were severe symptomatic aortic valve stenosis (defined as aortic valve area $<0.8 \mathrm{~cm}^{2}$ and mean transaortic gradient $>40 \mathrm{~mm} \mathrm{Hg}$ ) together with 1 or more of the following conditions: porcelain aorta; high surgical risk (logistic European System for Cardiac Operative Risk Evaluation [euroSCORE] I $>20 \%$ or Society of Thoracic Surgeons predicted risk of mortality $>10 \%$ ); or serious comorbidities, including chronic kidney failure, chronic obstructive pulmonary disease, previous total chest irradiation, hostile chest, or severe liver disease. The absolute contraindications for TA-TAVR were left ventricular aneurysm with or without thrombotic stratification and an extremely poor left ventricular ejection fraction $(\mathrm{LVEF})(<15 \%)$. All cases were evaluated by a multidisciplinary TAVR team that included a cardiac surgeon and an interventional cardiologist. Most centers that participate in the Italian Registry of Trans-Apical Aortic Valve Implantation (I-TA) registry adopt a "transfemoral first" policy. However, few centers follow a different strategy; thus, some patients received a TA-TAVR even without severe peripheral vascular disease. The procedures were performed under general anesthesia with orotracheal intubation in a hybrid operating room or a catheterization laboratory, according to the logistics of each center. In this study, we used the Sapien and, since mid-2010, the Sapien XT transcatheter valves (Edwards Lifesciences, Irvine, Calif). All details about the I-TA registry, including the cardiac surgery sites and investigators, TA-TAVR technique, device characteristics, sizing, postoperative medications, data collection, and analysis, have been described. ${ }^{1,10}$ Futility was defined as 1-year mortality in patients who did not experience 30-day all-cause mortality according to the Valve Academic Research Consortium definitions. ${ }^{15,16}$ Patients surviving 30 days after TA-TAVR were then divided into 2 groups: the futility (group F), including patients surviving less than 12 months, and the nonfutility (group NF), including patients surviving 12 months or more. Preoperative risk factors were defined according to the euroSCORE I classification. ${ }^{17}$ Preoperative rhythm disorders were defined as permanent atrial fibrillation or the presence of a definitive pacemaker.

\section{Statistical Analysis}

For continuous variables, data are reported as mean with standard deviation or median with interquartile range, according to the nature of variables distribution. For categoric variables, data are reported as frequency (percentage). Comparison between groups for continuous variables was made using the $t$ test or the Wilcoxon Mann-Whitney test as appropriate; comparison between groups for categoric variables was made using the chi-square or Fisher exact test as appropriate. Cox proportional hazard regression analysis was performed to identify independent predictors of futility that are reported as hazard ratio (HR), $95 \%$ confidence interval, and $P$ value. All statistical tests were 2-sided. Statistical analyses were conducted using SAS version 9.2 (SAS Institute, Inc, Cary, NC).

\section{RESULTS}

From April 2008 to June 2012, a total of 774 patients had been enrolled in the I-TA registry. For this study, we excluded from the analysis 77 patients $(9.9 \%)$ who experienced 30-day mortality and 52 patients $(6.7 \%)$ with a follow-up less than 12 months. We analyzed data from 645 patients with survival 30 days or more after TA-TAVR and at least 1-year follow-up. Group F included 60 patients $(10.8 \%)$, and group NF included 585 patients $(89.2 \%)$. Preoperative clinical variables are listed in Table 1. Age (F: $80.1 \pm 9.5$ years vs NF: $81.2 \pm 6.4$ years, $P=.4$ ) and sex (female sex, F: $50 \%$ vs NF: $58.8 \%, P=.18$ ) were not different between groups. Patients in group $\mathrm{F}$ were more likely to have diabetes $(41.7 \%$ vs $25.8 \%, P=.009)$ and insulin-dependent diabetes ( $15 \%$ vs $7.2 \%, P=.03)$; to have chronic kidney disease and in particular to have creatinine $2.0 \mathrm{mg} / \mathrm{dL}$ or greater or dialysis $(18.3 \%$ vs $8.2 \%, P=.01)$ and worse glomerular filtration rate 
TABLE 1. Preoperative clinical variables

\begin{tabular}{|c|c|c|c|c|}
\hline Variable & All patients $(n=645)$ & Group F $(n=60)$ & Group NF $(n=585)$ & $P$ value \\
\hline Age $(y, \%)$ & $81.2 \pm 6.4$ & $80.1 \pm 9.5$ & $81.2 \pm 6.4$ & .41 \\
\hline Sex (female, \%) & $374(58)$ & $30(50)$ & $344(58.8)$ & .18 \\
\hline Arterial hypertension (\%) & $554(85.9)$ & $50(83.3)$ & $535(91.5)$ & .55 \\
\hline Diabetes $(\%)$ & $176(27.3)$ & $25(41.7)$ & $151(25.8)$ & .009 \\
\hline Insulin treatment $(\%)$ & $51(7.9)$ & $9(15)$ & $42(7.2)$ & .03 \\
\hline \multicolumn{5}{|l|}{ NYHA class } \\
\hline I & $8(1.2)$ & $0(0)$ & $8(1.4)$ & .14 \\
\hline II & $101(15.7)$ & $5(8.3)$ & $98(16.8)$ & \\
\hline III & $341(52.9)$ & $39(65)$ & $301(51.5)$ & \\
\hline IV & $195(30.2)$ & $16(26.7)$ & $178(30.4)$ & \\
\hline PVD $(\%)$ & $308(47.8)$ & $30(50)$ & $278(47.5)$ & .71 \\
\hline COPD $(\%)$ & $208(32.2)$ & $21(35)$ & $187(32)$ & .63 \\
\hline Neurologic dysfunction (\%) & $52(8.1)$ & $5(8.3)$ & $47(8)$ & .94 \\
\hline CKD $(\%)$ & $59(9.1)$ & $1(18.3)$ & $48(8.2)$ & .001 \\
\hline GFR (mL/min) & $49.3 \pm 26.3$ & $40.4 \pm 16.9$ & $49.3 \pm 26.2$ & .001 \\
\hline Preoperative serum creatinine $(\mathrm{mg} / \mathrm{dL})$ & $1.2 \pm 0.6$ & $1.4 \pm 0.7$ & $1.2 \pm 0.6$ & .007 \\
\hline Liver cirrhosis $(\%)$ & $4(0.6)$ & $2(3)$ & $2(0.3)$ & .06 \\
\hline Preoperative rhythm disorders & & & & .032 \\
\hline $\mathrm{AF}(\%)$ & 139 (21.6) & $18(30)$ & $121(20.7)$ & \\
\hline $\mathrm{PM}(\%)$ & $33(5.1)$ & $6(10)$ & $27(4.6)$ & \\
\hline Critical preoperative state $(\%)$ & $16(2.5)$ & $5(8.3)$ & $11(1.9)$ & .002 \\
\hline $\mathrm{CAD}(\%)$ & $317(58)$ & $29(48.3)$ & $288(49.2)$ & .74 \\
\hline LVEF $(\%)$ & $53.7 \pm 12$ & $49 \pm 15.4$ & $53.7 \pm 12$ & .02 \\
\hline LVEF $<30 \%(\%)$ & $26(4)$ & $9(15)$ & $17(2.9)$ & $<.0001$ \\
\hline PAPs (mm Hg) & $42.4 \pm 13$ & $45.1 \pm 11.6$ & $42.4 \pm 12.9$ & .20 \\
\hline Severe MR (\%) & $112(17.4)$ & $14(23.3)$ & $98(16.8)$ & .06 \\
\hline Porcelain aorta $(\%)$ & $88(13.6)$ & $9(15)$ & $79(13.5)$ & .75 \\
\hline Previous cardiac surgery $(\%)$ & 141 (21.9) & $14(23.3)$ & 127 (21.7) & .77 \\
\hline Logistic euroSCORE $(\%)$ & $24.2 \pm 15.3$ & $30 \pm 17.8$ & $24.2 \pm 15.3$ & .008 \\
\hline STS PROM (\%) & $10 \pm 7.9$ & $11.8 \pm 5.6$ & $10 \pm 7.8$ & .28 \\
\hline Peak aortic gradient $(\mathrm{mm} \mathrm{Hg})$ & $81.7 \pm 21.9$ & $77.5 \pm 25.7$ & $81.7 \pm 21.9$ & .17 \\
\hline Mean aortic gradient $(\mathrm{mm} \mathrm{Hg})$ & $50.8 \pm 14.9$ & $47.4 \pm 16.6$ & $50.8 \pm 14.9$ & .01 \\
\hline $\operatorname{AVA}\left(\mathrm{cm}^{2}\right)$ & $0.7 \pm 0.2$ & $0.68 \pm 0.16$ & $0.74 \pm 0.17$ & .02 \\
\hline AVAi $\left(\mathrm{cm}^{2} / \mathrm{m}^{2}\right)$ & $0.4 \pm 0.1$ & $0.41 \pm 0.09$ & $0.44 \pm 0.1$ & .05 \\
\hline Aortic annulus diameter (mm) & $22.1 \pm 2$ & $21.9 \pm 2.1$ & $22.1 \pm 2$ & .54 \\
\hline
\end{tabular}

( $40.4 \pm 16.9 \mathrm{~mL} / \mathrm{min}$ vs $49.3 \pm 26.3 \mathrm{~mL} / \mathrm{min}, P=.001)$; to have lower LVEF $(49 \% \pm 15.4 \%, P=.02)$ and preoperative rhythm disorders ( $40 \%$ vs $25.3 \%, P=.03)$; and to be in a critical preoperative state $(8.3 \%$ vs $1.8 \%, P=.003)$. Logistic euroSCORE values were higher in group F $(30 \% \pm$ $17.8 \%$ vs $24.2 \% \pm 15.3 \%, P=.008$ ), although we did not observe differences in the Society of Thoracic Surgeons prediction of mortality $(11.8 \% \pm 5.6 \%$ vs $10 \% \pm 7.9 \%$, $P=.28$ ). Furthermore, patients in group $\mathrm{F}$ apparently had a more severe degree of aortic valve stenosis as confirmed by measurement of aortic valve area $\left(0.68 \pm 0.16 \mathrm{~cm}^{2}\right.$ vs $0.74 \pm 0.17 \mathrm{~cm}^{2}, P=.02$ ). Perioperative and postoperative outcomes are shown in Table 2. Perioperative data show that length of stay in the intensive care unit (median value, 24 hours in both groups, $P=.82$ ) and the hospital (median value, F: 10 days, NF: 8 days, $P=.72$ ) was not different between groups. The incidence of moderate and severe aortic regurgitation at discharge was significantly higher in group $\mathrm{F}(13.3 \%$ vs $5.6 \%, P=.02)$. The Valve Academic Research Consortium (VARC) combined safety end point at 30 days, which includes major stroke, life-threatening (or disabling) bleeding, acute kidney injury stage 3 (including renal replacement therapy), periprocedural myocardial infarction, major vascular complication, and repeat procedure for valve-related dysfunction (surgical or interventional therapy), was not different between groups because it occurred in $18.3 \%$ and $10.3 \%$ of patients in groups $\mathrm{F}$ and $\mathrm{NF}$, respectively $(P=.06)$. On the other hand, VARC-2 early safety at 30 days combined end point, which includes all strokes (disabling and nondisabling), life-threatening 
TABLE 2. Perioperative and postoperative outcomes

\begin{tabular}{|c|c|c|c|c|}
\hline & All patients $(n=645)$ & Group F $(\mathbf{n}=60)$ & Group NF $(\mathbf{n}=\mathbf{5 8 5})$ & $P$ value \\
\hline ICU LOS (h) (median and range) & $24(23-48)$ & $24(22-48)$ & $24(23-48)$ & .82 \\
\hline Hospital LOS (d) (median and range) & $8(7-12)$ & $10(7-14)$ & $8(7-12)$ & .72 \\
\hline Aortic PG (mm Hg) & $21 \pm 9.1$ & $20.5 \pm 11.6$ & $21 \pm 9$ & .80 \\
\hline Aortic MG (mm Hg) & $10.2 \pm 4.1$ & $9 \pm 3.8$ & $10.2 \pm 4$ & .05 \\
\hline $\operatorname{LVEF}(\%)$ & $54.3 \pm 9.8$ & $52 \pm 11.8$ & $54.3 \pm 9.8$ & .10 \\
\hline \multicolumn{5}{|l|}{ Intraoperative complications } \\
\hline Prosthesis embolization & $3(0.5)$ & 0 & $3(0.5)$ & 1.00 \\
\hline Need for CPB & $8(1.2)$ & $1(1.7)$ & $7(1.2)$ & .54 \\
\hline Need for sternotomy & $3(0.5)$ & 0 & $3(0.5)$ & 1.00 \\
\hline Access site complications & $7(1.1)$ & $1(1.7)$ & $6(1.0)$ & .50 \\
\hline Need for CPR & $11(1.7)$ & $2(3.3)$ & $9(1.5)$ & .27 \\
\hline Coronary occlusion & $2(0.3)$ & 0 & $2(0.3)$ & 1.00 \\
\hline Aortic dissection & $1(0.2)$ & 0 & $1(0.2)$ & 1.00 \\
\hline Need for valve-in-valve & $3(0.5)$ & 0 & $3(0.5)$ & 1.00 \\
\hline Postoperative AMI & $7(1.1)$ & $1(1.7)$ & $6(1.0)$ & .99 \\
\hline Postoperative stroke (all) & $4(0.6)$ & $2(3.3)$ & $2(0.4)$ & .09 \\
\hline Life-threatening bleeding & $44(6.8)$ & $8(13.3)$ & $36(6.1)$ & .04 \\
\hline AKIN grade $2-3$ & $49(12.7)$ & $6(16.0)$ & $43(12.4)$ & .41 \\
\hline Postoperative PPM implantation & $38(5.9)$ & $4(6.7)$ & $34(5.8)$ & .77 \\
\hline Moderate-severe AR at discharge (\%) & $41(6.4)$ & $8(13.3)$ & $33(5.6)$ & .02 \\
\hline VARC- 1 combined safety at $30 \mathrm{~d}(\%)$ & $71(11)$ & $11(18.3)$ & $60(10.3)$ & .06 \\
\hline VARC-2 early safety at $30 \mathrm{~d}(\%)$ & $91(14.1)$ & $14(23.3)$ & $77(13.2)$ & .03 \\
\hline
\end{tabular}

$A K I N$, Acute Kidney Injury Network; $A M I$, acute myocardial infarction; $A R$, aortic regurgitation; $C P B$, cardiopulmonary bypass; $C P R$, cardiopulmonary resuscitation; $F$, futility; $I C U$, intensive care unit; $L O S$, length of stay; $L V E F$, left ventricle ejection fraction; $M G$, mean gradient; $N F$, nonfutility; $P G$, peak gradient; $P P M$, permanent pacemaker implantation; VARC, Valve Academic Research Consortium.

bleeding, acute kidney injury stage 2 or 3 (including renal replacement therapy), coronary artery obstruction requiring intervention, major vascular complication, and valverelated dysfunction requiring repeat procedure was significantly higher in group $\mathrm{F}(23.3 \%$ vs $13.2 \%, P=.03)$. VARC-1 and VARC-2 safety end points at 30 days also include all-cause mortality, but this variable was not considered in the analysis because these patients were excluded from this study. Causes of cardiovascular and noncardiovascular mortality within 1 year after the operation are listed in Table 3. ${ }^{18}$ Among cardiovascular and noncardiovascular mortality, cardiac failure (13 patients, $21.7 \%$ ) and respiratory failure (11 patients, $18.3 \%$ ) are the 2 most common causes of death, respectively. The mean time from procedure to death of patients belonging to group $\mathrm{F}$ was $181 \pm 117$ days. To assess how preoperative variables affected postoperative outcomes but also to fully understand the impact of perioperative events on futility, in particular moderate-severe AR and safety end points, we performed the multivariate analysis in 4 different scenarios: on the entire cohort, with the exclusion of patients with AR $2+$ or greater, with the exclusion of patients with an early safety end point (according to VARC-2), and with the exclusion of patients with AR $2+$ or greater and patients with an early safety end point. Table 4 shows the results of the multivariate analysis. In particular, the multivariate analysis performed on the entire cohort identified the following independent predictors of futility: insulin-dependent diabetes (odds ratio [OR], 3.1; $P=.003$ ), creatinine $2.0 \mathrm{mg} / \mathrm{dL}$ or greater or dialysis (OR, 2.52; $P=.012$ ), preoperative rhythm disorders (OR, $1.88 ; P=.04)$, and LVEF less than $30 \%$ (OR, 4.34; $P=.001)$. If we exclude patients with postoperative AR $2+$ or greater from the analysis, insulin-dependent diabetes, chronic kidney disease, and poor LVEF are still independent predictors of futility, but rhythm disorders are not significant. On the other hand, when patients who experienced an early safety end point are excluded from the analysis, insulin-dependent diabetes and poor LVEF are still independent predictors of futility in association with preoperative critical state $(\mathrm{OR}, 3.58 ; P=.02)$. Last, when patients with postoperative AR $2+$ or greater and patients with an early safety end point are excluded from the multivariate analysis, insulin-dependent diabetes, critical preoperative state, and poor LVEF are still identified as independent predictors of futility in patients undergoing TA-TAVR. Therefore, insulin-dependent diabetes and poor LVEF are always identified as independent predictors of futility, whereas critical preoperative state and rhythm disorders, even if they do not reach the statistical significance in all the multivariate analyses, are predictors to note.

\section{DISCUSSION}

In this study, we analyzed data from the I-TA registry to identify preoperative independent predictors of futility in patients undergoing TA-TAVR. Futility was defined as 
TABLE 3. Causes of death

\begin{tabular}{|c|c|c|c|}
\hline \multicolumn{2}{|l|}{$\begin{array}{c}\text { Cardiovascular } \\
\text { mortality* }(n=25)\end{array}$} & \multicolumn{2}{|l|}{$\begin{array}{l}\text { Noncardiovascular } \\
\text { mortality* }(\mathbf{n}=\mathbf{3 5})\end{array}$} \\
\hline Cardiac failure & 13 & Lung disease & 11 \\
\hline Unknown & 4 & Infection, sepsis & 7 \\
\hline Sudden death/arrhythmias & 4 & Cancer & 5 \\
\hline Stroke & 1 & Cachexia, cognitive impairment & 4 \\
\hline AVSD & 1 & Acute renal insufficiency & 3 \\
\hline Pulmonary embolism & 1 & Cirrhosis & 2 \\
\hline Right myocardial infarction & 1 & Parkinson's disease & 2 \\
\hline & & Gastrointestinal bleeding & 1 \\
\hline
\end{tabular}

$\overline{A V S D \text {, Atrioventricular septal defect. *VARC definitions. }{ }^{15,16} \text { See Salizzoni and }}$ colleagues. $^{18}$

1-year mortality in patients surviving 30 days after TA-TAVR. The main findings of this analysis are that a futile procedure is performed in approximately $10 \%$ of patients undergoing TA-TAVR, that the majority of these patients die within 6 months after the operation, and that preoperative

TABLE 4. Preoperative risk factors for "futile" procedures at 1 year

\begin{tabular}{|c|c|c|c|}
\hline & HR & $95 \% \mathrm{CI}$ & $P$ value \\
\hline \multicolumn{4}{|l|}{ All patients, $\mathrm{n}=645$} \\
\hline Age & 1.000 & $0.965-1.035$ & .98 \\
\hline Gender female & 0.767 & $0.459-1.281$ & .31 \\
\hline IDDM & 2.343 & $1.134-4.041$ & .02 \\
\hline CKD & 1.978 & $1.012-3.865$ & .05 \\
\hline CPS & 1.970 & $0.684-5.671$ & .21 \\
\hline Rhythm disorders & 1.713 & $1.006-2.918$ & .05 \\
\hline $\mathrm{LVEF}<30$ & 3.267 & $1.418-7.531$ & .01 \\
\hline \multicolumn{4}{|c|}{ Postoperative $\mathrm{AR} \geq 2$ excluded, $\mathrm{n}=604$} \\
\hline Age & 0.993 & $0.960-1.027$ & .68 \\
\hline Gender female & 0.687 & $0.395-1.195$ & .18 \\
\hline IDDM & 2.619 & $1.252-5.475$ & .01 \\
\hline CKD & 2.068 & $1.007-4.246$ & .05 \\
\hline CPS & 2.680 & $0.888-8.092$ & .08 \\
\hline Rhythm disorders & 1.727 & $0.971-3.071$ & .06 \\
\hline LVEF $<30$ & 3.105 & $1.241-7.769$ & .02 \\
\hline \multicolumn{4}{|c|}{ VARC-2 early safety excluded, $\mathrm{n}=554$} \\
\hline Age & 1.032 & $0.987-1.080$ & .16 \\
\hline Gender female & 0.682 & $0.377-1.235$ & .21 \\
\hline IDDM & 3.525 & $1.623-7.654$ & .002 \\
\hline CKD & 1.144 & $0.438-2.990$ & .78 \\
\hline CPS & 3.581 & $1.216-10.544$ & .02 \\
\hline Rhythm disorders & 1.686 & $0.925-3.072$ & .09 \\
\hline LVEF $<30$ & 5.586 & $2.468-12.639$ & $<.001$ \\
\hline \multicolumn{4}{|c|}{ Postoperative AR $\geq 2$ and VARC- 2 early safety excluded, $n=520$} \\
\hline Age & 1.023 & $0.980-1.068$ & .30 \\
\hline Gender female & 0.713 & $0.379-1.341$ & .29 \\
\hline IDDM & 4.017 & $1.823-8.852$ & $<.001$ \\
\hline CKD & 1.368 & $0.505-3.704$ & .54 \\
\hline CPS & 4.221 & $1.386-12.861$ & .01 \\
\hline Rhythm disorders & 1.779 & $0.938-3.373$ & .08 \\
\hline LVEF $<30$ & 5.174 & $2.102-12.736$ & $<.001$ \\
\hline
\end{tabular}

$A R$, Aortic regurgitation; $C I$, confidence interval; $C K D$, chronic kidney disease; $C P S$, Critical Preoperative State (as defined by euroSCORE); $H R$, hazard ratio; IDDM, insulin-dependent diabetes mellitus; $L V E F$, left ventricular ejection fraction; VARC, Valve Academic Research Consortium. insulin-dependent diabetes, kidney function impairment, rhythm disorders, and poor LVEF may predict futility in this cohort of patients. Furthermore, critical preoperative state is another predictor of futility in patients who undergo an uneventful TA-TAVR operation followed by an uneventful postoperative hospital stay. What is futility in medicine? An action cannot be considered futile unless its goal is clearly stated. ${ }^{19}$ Futility is the lack of effectiveness or success in doing something because it does not provide appropriate, expected, or desired results. If the goal of TAVR in very high-risk patients is to treat aortic valve stenosis to improve a patient's life expectancy and then the patient dies earlier than expected, that procedure should be considered futile. Conversely, if the goal of the operation is to give a chance of survival to a patient whose bad prognosis is due to the natural history of the disease, that procedure is not futile even if the patient dies early. Things change if we only look at the financial cost-effectiveness aspect. In this case, a futile heart procedure is an operation that despite its costs in terms of financial, technical, and human resources does not prolong life duration or provide an improvement of patients' clinical conditions, even if it is successfully carried out. According to the recently published American Heart Association/American College of Cardiology guidelines for the management of patients with valvular heart disease, TAVR is recommended in patients with a predicted post-TAVR survival more than 12 months. ${ }^{20}$ The majority of studies that analyze cost-effectiveness of TAVR evaluate the number of QALYs to assess the incremental cost-effectiveness ratio per QALYs gained. QALY is a parameter that takes into consideration both survival and quality of life after the operation. ${ }^{21}$ QALYs gained after a TAVR operation range from 0.60 to $1.56 .^{22}$ Consequently, patients with a short postoperative survival have a negative impact under a costeffectiveness point of view. Another important aspect is that in patients deemed inoperable only for anatomic reasons (eg, porcelain aorta), the cost-effectiveness of TAVR is even more evident because it is likely that they do not have all the several associated diseases that are present in patients with high-risk scores due to multiple comorbidities. In the NF cohort, the variables that were independently associated with futility, insulin-dependent diabetes, chronic kidney disease, preoperative rhythm disorders, and poor LVEF were present in $7.2 \%, 8.2 \%, 25.3 \%$, and $2.9 \%$ of patients, respectively. This means that despite these factors, they did not undergo a futile procedure, and consequently TATAVR should not be denied in all patients presenting with these comorbidities. Therefore, a multidisciplinary careful evaluation of patient's global clinical state should be made before denying the procedure. Furthermore, in-depth preoperative counseling is mandatory to share the decision with patients and their families. It is interesting to observe that patients with a short postoperative survival had a higher rate of postoperative moderate-severe aortic regurgitation. These 
results confirm the findings of Schewel and colleagues, ${ }^{23}$ who report an increased mortality in TAVR cases within 6 months if an at least moderate paravalvular leak was accepted as the final result of the procedure. The impact of aortic regurgitation on survival after TAVR was first introduced by the 2-year Placement of Aortic Transcatheter Valve trial report, in which it appeared that the presence of paravalvular or total aortic regurgitation (mild, moderate, or severe vs none or trace) after TAVR was associated with increased late mortality and that the effect of aortic regurgitation on mortality was proportional to the severity of the regurgitation. ${ }^{24}$ It is still debated whether even mild insufficiency might have an impact on survival because in other studies it was not associated with an increase of late postoperative mortality. ${ }^{25}$ Patients dying within 1 year after TAVR also had a higher incidence of 30-day safety events, defined as following VARC-2 recommendations. This confirms the results of one of our previous studies from the I-TA registry. In that article, we showed that patients who experienced an intraoperative complication had a significantly lower 18month survival when compared with patients without any complication. ${ }^{10}$ However, to avoid a potentially confounding impact of perioperative adverse events on the interpretation of these results, we performed the multivariate analysis excluding patients with postoperative moderate-severe AR and patients with a perioperative adverse event. Insulindependent diabetes is always identified as an independent predictor of futility; therefore, it should be considered a strong one. Insulin-dependent diabetes has already been described as an independent predictor of adverse events after TAVR, in particular for death and myocardial infarction, and it has been claimed to be included in future TAVR-dedicated risk scores. $^{26}$ Critical preoperative state (defined as according to the euroSCORE definitions) becomes a strong predictor of futility in patients with uneventful surgery and hospital stay, but it should always be considered as an important factor because it is present in all the analyses even if it does not always reach statistical significance.

\section{Study Limitations}

A strong limitation of this study is that we do not have data about frailty and quality of life, which are important aspects of a patient's evaluation and may have an impact on patient survival after surgery. Furthermore, data on quality of life during follow-up might provide information about another important aspect of futility, other than death, that has not been taken into account in this study. We do not have a central echocardiographic Core-Lab, and adverse events were assigned by each participating center and not by an ad hoc committee.

\section{CONCLUSIONS}

According to our data, approximately $10 \%$ of patients who survive TA-TAVR die within 1 year after the operation.
Insulin-dependent diabetes, poor left ventricle ejection fraction, rhythm disorders, and chronic kidney disease are independent predictors of futility. Patients in a critical preoperative state have a higher risk to undergo a futile procedure even if the operation and subsequent hospital stay are totally uneventful. All these factors should be carefully considered when screening TA-TAVR cases to optimize clinical outcomes and to provide a comprehensive preoperative counseling to patients and their families.

\section{References}

1. D’Onofrio A, Salizzoni S, Agrifoglio M, Cota L, Luzi G, Tartara PM, et al. Medium term outcomes of transapical aortic valve implantation: results from the Italian Registry of Trans-Apical Aortic Valve Implantation. Ann Thorac Surg. 2013;96:830-5.

2. Ye J, Cheung A, Lichtenstein SV, Nietlispach F, Albugami S, Masson JB, et al. Transapical transcatheter aortic valve implantation: follow-up to 3 years. $J$ Thorac Cardiovasc Surg. 2010;139:1107-13.

3. Bleiziffer S, Mazzitelli D, Opitz A, Hettich I, Ruge H, Piazza N, et al. Beyond the short-term: clinical outcome and valve performance 2 years after transcatheter aortic valve implantation in 227 patients. J Thorac Cardiovasc Surg. 2012; 143:310-7.

4. Walther T, Kempfert J, Rastan A, Borger MA, Linke A, Ender J, et al. Transapical aortic valve implantation at 3 years. J Thorac Cardiovasc Surg. 2012;143: 326-31.

5. Unbehaun A, Pasic M, Drews T, Penkalla A, Dreysse S, Klein C, et al. Transapical aortic valve implantation: predictors of survival up to 5 years in 730 patients. An update. Eur J Cardiothorac Surg. March 5, 2014 [Epub ahead of print].

6. Orlando R, Pennant M, Rooney S, Khogali S, Bayliss S, Hassan A, et al. Costeffectiveness of transcatheter aortic valve implantation (TAVI) for aortic stenosis inpatients who are high risk or contraindicated for surgery: a model-based economic evaluation. Health Technol Assess. 2013;17:1-86.

7. O'Sullivan CJ, Stortecky S, Buellesfeld L, Wenaweser P, Windecker S. Preinterventional screening of the TAVI patient: how to choose the suitable patient and the best procedure. Clin Res Cardiol. 2014;103:259-74.

8. Reynolds M, Magnusson E, Lei Y, Wang K, Vilain K, Li H, et al. Cost-effectiveness of transcatheter aortic valve replacement compared with surgical aortic valve replacement in high-risk patients with severe aortic stenosis. J Am Coll Cardiol. 2012;60:2683-90.

9. Cao C, Ang S, Indraratna P, Manganas C, Bannon P, Black D, et al. Systematic review and meta-analysis of transcatheter aortic valve implantation versus surgical aortic valve replacement for patients with severe aortic stenosis. Ann Cardiothorac Surg. 2013;2:10-23.

10. D’ Onofrio A, Rubino P, Fusari M, Salvador L, Musumeci F, Rinaldi M, et al. Clinical and hemodynamic outcomes of "all-comers" undergoing transapical aortic valve implantation: results from the Italian Registry of Trans-Apical Aortic Valve Implantation (I-TA). J Thorac Cardiovasc Surg. 2011;142:768-75.

11. Moat NE, Ludman P, de Belder MA, Bridgewater B, Cunningham AD, Young CP, et al. Long-term outcomes after transcatheter aortic valve implantation in high-risk patients with severe aortic stenosis: the U.K. TAVI (United Kingdom Transcatheter Aortic Valve Implantation) Registry. J Am Coll Cardiol. 2011;58:2130-8.

12. Rodés-Cabau J, Webb JG, Cheung A, Ye J, Dumont E, Feindel CM, et al. Transcatheter aortic valve implantation for the treatment of severe symptomatic aortic stenosis in patients at very high or prohibitive surgical risk: acute and late outcomes of the multicenter Canadian experience. J Am Coll Cardiol. 2010;55: 1080-90.

13. Wenaweser P, Pilgrim T, Roth N, Kadner A, Stortecky S, Kalesan B, et al. Clin ical outcome and predictors for adverse events after transcatheter aortic valve implantation with the use of different devices and access routes. Am Heart J. 2011 ; 161:1114-24.

14. Thomas M, Schymik G, Walther T, Himbert D, Lefèvre T, Treede H, et al. Oneyear outcomes of cohort 1 in the Edwards SAPIEN Aortic Bioprosthesis European Outcome (SOURCE) registry: the European registry of transcatheter aortic valve implantation using the Edwards SAPIEN valve. Circulation. 2011;124: 425-33.

15. Leon MB, Piazza N, Nikolsky E, Blackstone EH, Cutlip DE, Kappetein AP, et al. Standardized endpoint definitions for transcatheter aortic valve implantation 
clinical trials: a consensus report from the Valve Academic Research Consortium. J Am Coll Cardiol. 2011;57:253-69.

16. Kappetein AP, Head SJ, Généreux P, Piazza N, van Mieghem NM, Blackstone EH, et al. Updated standardized endpoint definitions for transcatheter aortic valve implantation: the Valve Academic Research Consortium-2 consensus document. J Thorac Cardiovasc Surg. 2013;145:6-23.

17. Nashef SA, Roques F, Michel P, Gauducheau E, Lemeshow S, Salamon R. European system for cardiac operative risk evaluation (EuroSCORE). Eur J Cardiothorac Surg. 1999;16:9-13.

18. Salizzoni S, Grosso Marra W, Moretti C, D’Amico M, La Torre MW, Rinaldi M. An iatrogenic atrioventricular septal defect that developed following transfemoral TAVI. J Heart Valve Dis. 2014;23:216-8.

19. Prager K. When physicians and surrogates disagree about futility. Virtual Mentor. 2013;15:1022-6.

20. Nishimura RA, Otto CM, Bonow RO, Carabello BA, Erwin JP III, Guyton RA, et al. 2014 AHA/ACC Guideline for the Management of Patients With Valvular Heart Disease: Executive Summary: A Report of the American College of Cardiology/American Heart Association Task Force on Practice Guidelines. J Am Coll Cardiol. 2014;63:2438-88.

21. Weintraub WS, Barnett P, Chen S, Hartigan P, Casperson P, O'Rourke R, et al. Economics methods in the Clinical Outcomes Utilizing percutaneous coronary Revascularization and Aggressive Guideline-driven drug Evaluation (COURAGE) trial. Am Heart J. 2006;151:1180-5.

22. Indraratna P, Ang SC, Gada H, Yan TD, Manganas C, Bannon P, et al. Systematic review of the cost-effectiveness of transcatheter aortic valve implantation. $J$ Thorac Cardiovasc Surg. November 23, 2013 [Epub ahead of print].

23. Schewel D, Frerker C, Schewel J, Wohlmuth P, Meincke F, Thielsen T, et al. Clinical impact of paravalvular leaks on biomarkers and survival after transcatheter aortic valve implantation. Catheter Cardiovasc Interv. November 21, 2013 [Epub ahead of print].

24. Kodali SK, Williams MR, Smith CR, Svensson LG, Webb JG, Makkar RR, et al. Two-year outcomes after transcatheter or surgical aortic-valve replacement. $N$ Engl J Med. 2012;366:1686-95.

25. Zahn R, Gerckens U, Linke A, Sievert H, Kahlert P, Hambrecht R, et al. Predictors of one-year mortality after transcatheter aortic valve implantation for severe symptomatic aortic stenosis. Am J Cardiol. 2013;112:272-9.

26. Conrotto F, D'Ascenzo F, Giordana F, Salizzoni S, Tamburino C, Tarantini G, et al. Impact of diabetes mellitus on early and midterm outcomes after transcatheter aortic valve implantation (from a multicenter registry). Am J Cardiol. 2014; 113:529-34.

\section{Discussion}

Dr Wilson Szeto (Philadelphia, $\mathrm{Pa}$ ). I congratulate you on a well-done study. My disclosure is that I am an investigator in the PARTNER trial at our institution at the University of Pennsylvania.

This presentation is a timely and important topic. We have all struggled with the question of futility versus utility in these patients. The so-called eyeball test is what you are referring to; how do we determine which patients are "too sick" for even TAVR?

I applaud you and agree with you in your multivariate analysis that we have now learned that factors such as end points in VARC2 and mild paravalvular leak may have a late impact on outcome. I applaud you for an in-depth analysis eliminating those factors when you examine your multivariate analysis predictors of death.

One of the issues that we have struggled with over the last few years in terms of determining what is considered futile is this whole question of an "eyeball test" and noncardiac factors that are not captured in the Society of Thoracic Surgeons predicted risk of mortality, such as frailty, dementia, cirrhosis. Do you have any information to share with us regarding these factors in your patient cohort, and what impact do you think there would have been on your analysis?

Dr D'Onofrio. We don't have data about frailty in this registry. Frailty is difficult to quantify, especially in patients undergoing cardiac surgery, because there are no specific scores for them.
There are so many different scores, and these evaluations are subjective. I cannot answer this question because I don't have data on frailty, but it would be interesting to analyze this aspect.

Regarding cirrhosis, we had only 4 patients in this population ( 2 in group $\mathrm{F}$ and 2 in group NF), and these numbers are too small to evaluate the impact of this variable on postoperative outcomes.

We believe that dementia is a contraindication to a transcatheter aortic valve implantation, because it would not improve quality of life or patient survival. We don't usually perform TAVI in patients with dementia.

Dr Szeto. Another important outcome that we have all looked at in TAVR is the question of functional recovery and quality of life. Do you have any data to share with us regarding the 2 groups, the $F$ and NF groups? Were there any differences in those metrics in your study?

Dr D'Onofrio. It is difficult to compare these groups in terms of functional recovery, because the group " $F$ " has a short follow-up. By looking at the data, we observed that $40 \%$ of patients in group $\mathrm{F}$, futile patients, died of cardiovascular causes. So I suppose the functional recovery is worse in these patients. But it is difficult to compare the 2 groups, because these patients have only 6 months follow-up, and the other patients have 4 to 5 years follow-up.

It would be interesting to analyze these patients in terms of quality of life, because this is another important aspect of futility. Unfortunately, we don't have data on quality of life. It would be interesting to analyze futility not only in terms of survival but also in terms of quality of life. So if somebody in the audience has these data and would like to share it with us, we could extend this study and maybe present it next year.

Dr Szeto. From a practical standpoint in terms of how you evaluate patients in your valve clinic, on the basis of your data, what would you recommend to the rest of us as we try to better sort out which patients are futile and which patients we should treat? What would you recommend at this point? You alluded to it a bit at the end of your presentation.

Dr D'Onofrio. If we honestly believe that a patient would not improve quality of life or survival with a TAVI, we have to deny TAVR to that patient. It is crucial to comprehensively counsel patients and their families. We don't think that all patients with these predictors of futility should be excluded tout court from this procedure. There are, as I showed in the slides, a lot of patients who, despite chronic kidney disease and with rhythm disorders that are predictors of futility, had a good outcome after the procedure. So it is not a good reason to exclude these patients only because they have these risk factors. Good counseling and more attention to their procedure and immediate postoperative period are recommended.

Dr Harold Lazar (Boston, Mass). What type of patients would you say no to on the basis of your study? What type of patients would you not offer this technique to?

Dr D'Onofrio. It is impossible to identify exactly what kind of patients we should say no to. We have to evaluate many things, such as risk factors and general clinical conditions. The "eyeball test" is important, especially now that we have some good experience with these patients. Taking into account all these factors, we should be able to understand which patients are more likely to have a poor postoperative outcome. 
Dr Lazar. So a 75-year-old patient who is intubated, with congestive heart failure, inotropes, and worsening kidney function, would you operate on that patient?

Dr D'Onofrio. If the patient is in an acute phase of disease and the main cause of the condition is aortic valve disease, I would operate on this patient. I would not operate on a 92 -year-old patient who has chronic kidney disease, poor mobility, and all the other well-known associated conditions; to me, this makes no sense. But if, like you said, a 75-year-old patient has acute heart failure, I would do it, and actually we did it with good results.

Dr A. Pieter Kappetein (Rotterdam, The Netherlands). The title of your presentation is great, and listening to your presentation I thought, "He is finally going to tell me which patients not to treat." But what you tell us is that diabetes, LVEF, high pulmonary pressure, kidney disease, and conduction disturbances are not good. So which of those predictive factors were not surprising and which were new to you?

Dr D'Onofrio. That is a good point. I would have expected functional class to be an independent predictor of a bad outcome, and I would have also expected euroSCORE to be a predictor of a bad outcome. In our previous articles, euroSCORE and functional class were identified as risk factors for mortality, so I would have expected that these factors would have been significant in these patients also.

Dr Kappetein. This is important, because you can teach us which variables we should not take into account, for example, euroSCORE. Is that what you mean?

Dr D'Onofrio. Correct.

Dr Kappetein. This means that we should not take into account the euroSCORE. Is that what you mean?
Dr D'Onofrio. It seems that just some of the variables that are included in the euroSCORE should be taken into account, but not the euroSCORE itself.

Dr Kappetein. Why do you think the euroSCORE is not predictive then? What is the reason for that?

Dr D'Onofrio. Probably because it takes into account a lot of variables that don't have an impact on these particular patients, and it is not tailored specifically for these high-risk patients with aortic disease.

Dr Kappetein. So don't use the euroSCORE in these types of patients?

Dr D'Onofrio. Well, use it, but rather look at each single variable included in the euroSCORE. Furthermore, look at the patient in all aspects.

Dr Lazar. One final quick question. You have been putting these in, or the registry has documented these, since 2008 ?

Dr D'Onofrio. Yes.

Dr Lazar. Can you give us some idea what the freedom from structural deterioration of these valves are and what percent have had to be replaced?

Dr D'Onofrio. We just updated this registry, and now we have approximately 1000 patients. We have approximately 5 years follow-up with a mean follow-up of approximately 2.5 years, and we haven't observed any structural valve deterioration so far. However, the duration of follow-up is still too short.

Dr Lazar. Paravalvular leaks?

Dr D'Onofrio. Paravalvular leaks are approximately $40 \%$, including mild, moderate, and severe. In particular, moderate and severe leaks occurred in approximately $8 \%$ of patients, and they have a significant impact on survival in our registry. 